Nota

\title{
USO DAS TERRAS DA PARTE NORTE DA BACIA DO RIO DESCOBERTO, DISTRITO FEDERAL, BRASIL (1)
}

\author{
AURÉLIO ALVES AMARAL CHAVES $\left({ }^{2}\right)$; MARILUSA PINTO COELHO LACERDA $\left({ }^{2 *}\right)$; \\ EIYTI KATO $\left({ }^{2}\right)$; WENCESLAU J. GOEDERT $\left({ }^{2}\right)$; MARIA LUCRÉCIA GEROSA RAMOS $\left({ }^{2}\right)$
}

\begin{abstract}
RESUMO
Este trabalho teve como objetivo avaliar o uso das terras da porção norte da Área de Proteção Ambiental do Rio Descoberto, englobando as microbacias dos Córregos Barrocão, Bucanhão e Capão da Onça, com auxílio de técnicas de geoprocessamento. Elaborou-se o mapa de uso das terras a partir de processamentos da imagem de satélite SPOT 4, obtida em 2003, por meio do software ENVI 3.6. Posteriormente, verificou-se a adequabilidade do uso das terras, com base em técnicas de cruzamento e operações de tabulação cruzada entre os mapas de uso e aptidão agrícola das terras, utilizando-se o software ArcView 8.3, permitindo a geração do mapa de adequabilidade de uso das terras. Pelos resultados, constatou-se que a maior parte da área estudada a utilização das terras está abaixo do seu potencial agrícola, caracterizando sustentabilidade da utilização dos recursos naturais, particularmente solos.
\end{abstract}

Palavras-chave: aptidão agrícola, geoprocessamento, microbacias, sensoriamento remoto, sistemas de informações geográficas.

\section{ABSTRACT \\ LAND USE IN THE NORTHERN REGION OF THE DESCOBERTO RIVER WATERSHED, DISTRITO FEDERAL, BRAZIL}

This work had the objective to evaluate the land use in the northern region of the Environmental Protection Area of Descoberto River, which encompasses the watersheds of the streams Barrocão, Bucanhão and Capão da Onça, accomplished with the support of geoprocessing techniques. A land use map of the area was produced through analysis and treatment of SPOT 4 satellite images, obtained in 2003, using the software ENVI 3.6. Then, the adequation of land use was checked using cross-tabulation between the maps of present and potential use for agriculture, with the software ArcView 8.3, allowing development of a map of land use suitability. The results showed that most of the area has been used under its agricultural potential, characterizing sustainability in the use of the natural resources, particularly of the soils.

Key words: land capability, geoprocessing, watersheds, remote sensing, geographical information system.

(1) Projeto financiado pelo CNPq. Recebido para publicação em 11 de maio de 2009 e aceito em 2 de março de 2010.

$\left(^{2}\right)$ Faculdade de Agronomia e Medicina Veterinária - Universidade de Brasília, Campus Darcy Ribeiro, ICC Ala Sul, Caixa postal 4508, 70910-960 Brasília (DF). E-mail: aaa.chaves@hotmail.com; marilusa@unb.br ${ }^{*}$ ) Autora correspondente; goedert@unb.br; lucrecia@unb.br; kato@unb.br. 
A utilização das terras e o crescimento econômico têm sido constantemente prejudicados pela falta de planejamento racional, que tenha como base o conhecimento dos recursos naturais disponíveis. A exploração desordenada contribui para a degradação dos ecossistemas regionais com conseqüente deterioração do nível de vida da população rural e urbana.

Segundo Hernandez FilHo et al. (1998), o conhecimento dos componentes naturais e dos processos que ocorrem nos sistemas ambientais, possibilita a previsão de desequilíbrios causados pelas diversas atividades e subsidiam políticas direcionadas para uma ocupação ordenada.

A preocupação com o uso da terra é um dos primeiros passos na direção de uma agricultura sustentável (LEPSCH et al., 1983). O Sistema de Avaliação da Aptidão Agrícola das Terras (RAmalho Filho e BeEK, 1995) constitui base para uma exploração racional das terras, otimizando seu uso pelo máximo de tempo possível e tem sido muito empregado na avaliação da adequabilidade do uso das terras.

Vários trabalhos vêm sendo desenvolvidos para a verificação da adequação do uso e ocupação das terras utilizando técnicas de geoprocessamento. SILVA et al. (1999) quantificaram, por meio de Sistema de Informações Geográficas (SIG), as classes de ocupação do meio físico da microbacia Quatro Bocas, em Angelin (PE). PEDRON et al. (2006) determinaram a aptidão, uso atual e os conflitos decorrentes da utilização das terras, visando contribuir para o planejamento racional dos recursos naturais do município de São João do Polêsine (RS). SILVA (2003) avaliou a adequação do uso atual das terras na Microbacia João Leite, GO.

Diante de problemas ambientais relacionados aos diferentes usos e ocupações das terras no Distrito Federal, particularmente no sistema de abastecimento de água do Rio Descoberto, nota-se a necessidade de avaliação da sustentabilidade do uso das terras das microbacias que contribuem diretamente para o Reservatório do Descoberto, que abastece cerca de $60 \%$ da população do Distrito Federal e entorno (FONSECA, 2001).

Neste contexto, o presente trabalho objetivou diagnosticar o uso e a ocupação das terras das microbacias dos córregos Barrocão, Bucanhão e Capão da Onça, pertencentes à Área de Proteção Ambiental do Rio Descoberto, com o auxílio de tecnologias de Sensoriamento Remoto e de Sistemas de Informação Geográficas.

A área selecionada para o estudo localiza-se na porção norte da Área de Proteção Ambiental (APA) do Rio Descoberto, englobando as microbacias dos Córregos Barrocão, Bucanhão e Capão da Onça, situada na Região Administrativa de Brazilândia, no Distrito Federal-DF (Figura 1). A área estudada possui 6.583 hectares e situa-se entre as coordenadas UTM (fuso 22) $795.624 \mathrm{~m}$ e $807.260 \mathrm{~m} ; 8.261 .264 \mathrm{~m}$ e $8.272 .752 \mathrm{~m}$.

Nesta área, o relevo é predominantemente plano a suave ondulado, com desenvolvimento de vegetação natural de Cerrado, com ocorrência de Latossolos Vermelhos e Latossolos Vermelho-Amarelos.

Com relação à análise espacial, os dados digitais de curvas de nível, pontos cotados e hidrografia foram obtidos das bases cartográficas do IBGE, 1994, na escala de 1:25.000. O mapa de solos e o de aptidão agrícola das terras, na escala de 1:100.000, foram extraídos do Levantamento de Reconhecimento de Solos do Distrito Federal (EMBRAPA,1978).

O mapa de uso das terras da área de trabalho foi gerado a partir de processamentos, interpretação e classificação não supervisionada da imagem de satélite SPOT 4, de setembro de 2003, em composição colorida das bandas 1, 2, 3 e pancromática, em RGB, por meio do software ENVI 3.6. O método de classificação, utilizado foi o ISODATA ("Interative Self-Organizing Data Analysis Technique"), que usa uma fórmula de distância espectral mínima para formar as classes (grupos) que correspondem à maior similaridade espectral entre os grupos de pixels. O ISODATA inicia com agrupamentos arbitrários (grupos-padrão) e a cada vez que os agrupamentos são formados, repetidamente, a maneira de agrupar é modificada, chegando a uma diferença espectral mínima entre os grupos de pixels. Um exemplo de utilização deste método foi o trabalho de avaliação de uso do solo e tipos de água no reservatório de Manso, MT, desenvolvido por VALÉRIO et al (2008).

Em princípio, a imagem foi classificada em 12 classes, que após checagens de campo, foram posteriormente combinadas, utilizando-se o software ENVI 3.6, gerando as seguintes classes de uso e ocupação das terras: Área Urbana, Mata (de galeria, ciliar e reflorestamento), Cerrado, Pastagem, Agricultura e Solo Desnudo. A classe denominada Agricultura corresponde a conjuntos de pequenas chácaras, com plantios predominantemente de hortaliças em pequenos talhões, sem uniformização de técnicas de manejo.

A classe de ocupação denominada Pastagem agrupa tanto pastagens naturais quanto pastagens plantadas, uma vez que a resposta espectral de ambas é semelhante, não sendo diferenciada pelo sensor utilizado. Pelo mesmo motivo, a classe Mata engloba áreas de reflorestamento e zonas ripárias.

A adequação do uso e ocupação dos solos foram avaliadas por meio de técnicas de cruzamento eoperações 




Figura 1: Mapa de localização da área estudada na porção norte da APA do Rio Descoberto.

de tabulação cruzada entre o mapa temático de uso e a ocupação das terras, gerado neste trabalho e o mapa de aptidão agrícola das terras (EMBRAPA, 1978) apresentado na figura 2, ambos convertidos para o formato grid ou matricial, utilizando o módulo Spatial Analyst do software ArcView 8.3. Foi analisado apenas o nível de manejo B do Sistema de Aptidão Agrícola das Terras, que reflete o nível tecnológico intermediário que corresponde ao nível observado na área de estudo. A classe de uso Solo Desnudo foi associada à Agricultura, pois representa as áreas preparadas para cultivos e a classe Área Urbana foi desconsiderada, uma vez que não se trata de área agrícola, sendo avaliada em conjunto com as áreas de Cerrado. Com este cruzamento, foi gerado o mapa de adequabilidade de uso das terras, com identificação de áreas com as seguintes classificações:

Uso adequado: uso das terras de acordo com sua aptidão agrícola;

Uso acima do potencial: uso das terras mais intensivo que sua aptidão agrícola;

Uso abaixo do potencial: uso das terras menos intensivo que sua aptidão agrícola.
Ressalta-se que a avaliação do uso das terras por meio desta metodologia apresenta caráter regional.

Após várias etapas de avaliações e interpretações da imagem de satélite SPOT da área por meio do software ENVI 3.6, acompanhadas por checagens de campo, foi possível estabelecer o mapa de uso das terras da área de estudo por intermédio do método de classificação ISODATA, que foi eficiente para o objetivo proposto, individualizando as classes estabelecidas de uso e ocupação das terras: Área Urbana, Mata (de galeria, ciliar e reflorestamento), Cerrado, Pastagem, Agricultura e Solo Desnudo, conforme pode ser visualizado na figura 3. O resultado foi compatível, em termos de qualidade, com o dos trabalhos desenvolvidos por SiLva (2003) e Lово (2002), entre tantos outros, que também utilizaram imagens de satélites para caracterizar as diferentes classes de uso das terras das respectivas áreas de estudo.

Os resultados da tabulação cruzada entre os mapas de uso das terras gerado neste trabalho (Figura 3) e da aptidão agrícola estão apresentados na tabela 1, podendo-se avaliar se as classes de uso estabelecidas estão em acordo com a aptidão agrícola das terras no nível de manejo B (RAMalHo Filho e BeEK, 1995). As áreas 




Figura 2: Mapa de aptidão agrícola das terras da área estudada na porção norte da APA do Rio Descoberto. Fonte: Embrapa (1978).

de Cerrado que ocorrem na área correspondem, em sua maioria, às áreas remanescentes de vegetação nativa da Área de Proteção Ambiental (APA) do Rio Descoberto.

A avaliação dos dados obtidos pela tabulação cruzada (Tabela 1), permite concluir que 3.163 ha, totalizando $48,05 \%$ da área estudada, estão sendo ocupados para pastagens, mas poderiam ser utilizados para a agricultura, visto que nas terras correspondentes, as classes de aptidão agrícola regulares ( $1 b$ e $2 b)$ e restritas 2(b) estão sendo utilizadas abaixo do seu potencial agrícola. Os 3.163 ha correspondem ao somatório de 19,25 ha (Classe de aptidão agrícola $1 \mathrm{~b}$ versus Pastagem), com 17 ha (Classe $2 \mathrm{~b}$ versus Pastagem) e 3.126,75 ha (Classe 2(b) versus Pastagem).

Entretanto, as terras com agricultura estão sendo utilizadas adequadamente, dentro do seu potencial agrícola, ocupando $1.168,5$ ha da área de estudo, correspondente ao somatório de 47,75 ha (Classe de aptidão agrícola $1 \mathrm{~b}$ versus Agricultura), com 8,50 ha (Classe 2b versus Agricultura) e 1.112,25 ha (Classe 2(b) versus Agricultura), totalizando 17,75\% da área de trabalho.

Observa-se por meio dos dados apresentados na tabela 1, que 417,25 ha correspondentes a 6,35\% da área, estão sendo utilizados acima do potencial agrícola, ou seja, em desacordo com a aptidão agrícola das terras. Este total diz respeito ao somatório de 7,5 ha (Classe de aptidão agrícola $4 p$ versus Agricultura), 122,5 ha (Classe 5(n) versus Agricultura), 165 ha (Classe 6 versus Pastagem) e 122,25 ha (Classe 6 versus Agricultura).

Constata-se, ainda, que as áreas ocupadas por vegetação nativa estão em terras de classes de aptidão agrícola diversificadas. Do ponto de vista conservacionista, estas áreas colaboram para a sustentabilidade ambiental. Porém, sob uma avaliação agronômica, pode-se dizer que estas áreas estão sendo utilizadas abaixo do seu potencial agrícola. Estas áreas correspondem ao total de 1.379 ha ou $20,96 \%$ da área de trabalho e representam o somatório de 2,75 ha (Classe de aptidão agrícola $1 \mathrm{~b}$ versus Mata), 15,75 ha (Classe 


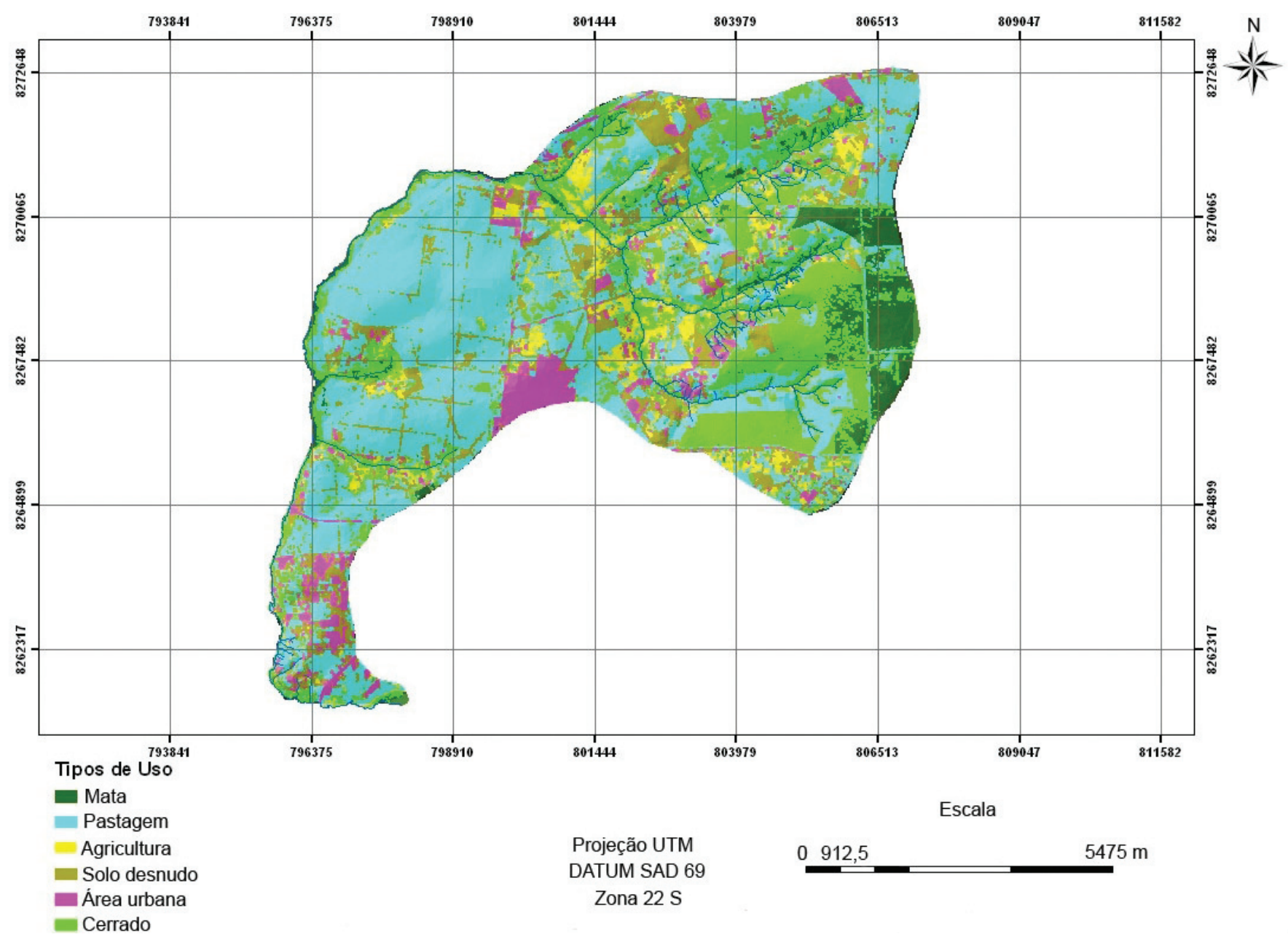

Figura 3: Mapa de uso e ocupação das terras da área estudada na parte norte da APA do Rio Descoberto.

Tabela 1. Comparação entre as classes de aptidão agrícola e o uso das terras, na porção Norte da APA do Rio Descoberto (DF)

\begin{tabular}{|c|c|c|c|c|c|c|c|c|c|c|c|c|c|c|}
\hline \multirow{3}{*}{ Uso } & \multicolumn{12}{|c|}{ Aptidão Agrícola } & \multirow{2}{*}{\multicolumn{2}{|c|}{ Total }} \\
\hline & \multicolumn{2}{|c|}{$1 \mathrm{~b}$} & \multicolumn{2}{|c|}{$2 b$} & \multicolumn{2}{|c|}{ 2(b) } & \multicolumn{2}{|c|}{$4 p$} & \multicolumn{2}{|c|}{$5(n)$} & \multicolumn{2}{|c|}{6} & & \\
\hline & $\%$ & ha & $\%$ & ha & $\%$ & ha & $\%$ & ha & $\%$ & ha & $\%$ & ha & $\%$ & ha \\
\hline MT & 0,04 & 2,75 & 0,27 & 17,50 & 9,43 & 621,00 & 0,11 & 7,00 & 0,19 & 12,50 & 0,64 & 42,25 & 10,68 & 703,00 \\
\hline PT & 0,29 & 19,25 & 0,26 & 17,00 & 47,50 & $3.126,75$ & 0,29 & 19,00 & 4,10 & 270,00 & 2,51 & 165,00 & 54,94 & $3.617,00$ \\
\hline $\mathrm{AG}$ & 0,72 & 47,75 & 0,14 & 8,50 & 16,89 & $1.112,25$ & 0,13 & 7,50 & 1,86 & 122,50 & 1,85 & 122,25 & 21,59 & $1.420,75$ \\
\hline $\mathrm{CE}$ & 0,24 & 15,75 & 0,38 & 25,00 & 9,37 & 616,75 & 0,17 & 11,25 & 0,95 & 62,25 & 1,69 & 111,25 & 12,79 & 842,25 \\
\hline $\mathrm{T}$ & 1,29 & 85,50 & 1,05 & 68,00 & 83,19 & $5.476,75$ & 0,70 & 44,75 & 7,10 & 467,25 & 6,68 & 440,75 & 100 & $6.583,00$ \\
\hline
\end{tabular}

$\left({ }^{1}\right) \mathrm{MT}=$ Mata; $\mathrm{PT}=$ Pastagem; $\mathrm{AG}=$ Agricultura; $\mathrm{CE}=$ Cerrado; $\mathrm{T}=$ Total.

$1 \mathrm{~b}$ versus Cerrado), 17,50 ha (Classe $2 \mathrm{~b}$ versus Mata), 25 ha (Classe $2 b$ versus Cerrado), 621 ha (Classe 2(b) versus Mata), 616,75 ha (Classe 2(b) versus Cerrado), 7 ha (Classe $4 \mathrm{p}$ versus Mata), 11,25 ha (Classe $4 \mathrm{p}$ versus Cerrado) e 62,25 ha (Classe 5n versus Cerrado).

Os dados obtidos revelam que na área de estudo, que totalizam $6.583 \mathrm{ha}, 23,83 \%$ (1.568,75 ha) das terras estão sendo utilizados de acordo com a aptidão agrícola.
Já 76,16\% da área são utilizados em desacordo com seu potencial agrícola, sendo 69,01\% (4.542,75 ha) em uso abaixo do seu potencial e 7,16\% (471,5 ha) utilizados acima do potencial.

O cruzamento entre o mapa de uso das terras e o mapa de aptidão agrícola, por meio do software ArcView 8.3, permitiu a geração do mapa representativo da adequabilidade de uso das terras da área estudada, 


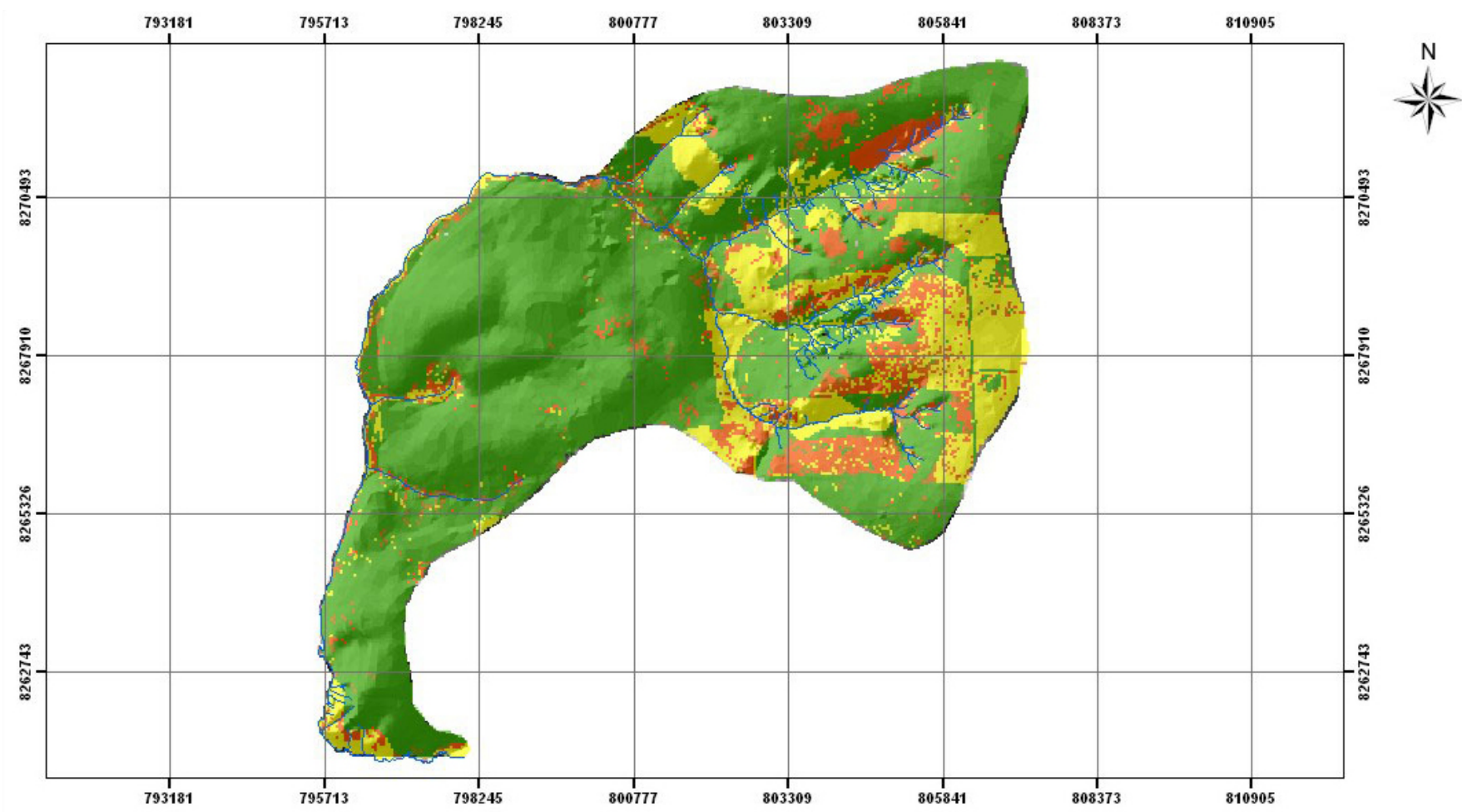

Escala

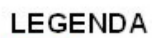

Uso acima do potencial agrícola

Uso agrícola adequado

Uso abaixo do potencial agrícola

Projeção UTM

DATUM SAD 69

Zona $22 \mathrm{~S}$

Figura 4: Mapa de adequabilidade do uso e ocupação das terras na parte norte da APA do Rio Descoberto.

apresentado na figura 4. Constitui uma representação do uso das terras da área de estudo que considera seus potenciais agrícolas, havendo áreas com uso acima e abaixo do potencial e as áreas com o uso adequado em relação ao potencial agrícola das terras.

Pelo diagnóstico do uso das terras constatouse que a ocupação da APA do Rio Descoberto não é intensiva, fato relevante considerando tratar-se de uma bacia de captação de água para consumo da população do DF.

Por meio da avaliação da adequabilidade do uso e ocupação das terras das microbacias da parte norte da bacia do Rio Descoberto-DF, englobando as microbacias dos córregos Barrocão, Bucanhão e Capão da Onça, permitiu-se constatar que em $69,01 \%$ da área as terras têm uso abaixo dos seus potenciais; no entanto, foram constatadas $7,16 \%$ da área com uso mais intensivo que suas respectivas aptidões agrícolas, indicativas de utilização inadequada das terras, comprometendo a sustentabilidade ambiental.

\section{REFERÊNCIAS}

EMBRAPA. Levantamento de reconhecimento dos solos do Distrito Federal. Rio de Janeiro: Embrapa - SNLCS, 1978. 455p. (Boletim Técnico, n. ${ }^{\circ} 53$ )

FONSECA, F.O. (Org.). Olhares sobre o Lago Paranoá. 1.ed. Brasília: Secretaria de Meio Ambiente e dos Recursos Hídricos, 2001. 425p.

HERNANDEZ FILHO, P.; PONZONI, F. J.; PEREIRA, M. N. Mapeamento da fitofisionomia e do uso da terra de parte da bacia do Alto Taquari mediante o uso de imagens TM/Landsat e HRV / SPOT. Pesquisa Agropecuária Brasileira, v.33, p.17551762, 1998.

LEPSCH, I.F.; BELINAZZI JUNIOR, R.; BERTOLINI, D.; ESPINDOLA, C.R. Manual para levantamento utilitário do meio físico e classificação de terras no sistema de capacidade de uso. Campinas: SBCS, 1983. 175p.

LOBO, G.A.S. Aplicação de geotecnologias no planejamento de uso de áreas rurais. 2002, 144p. Dissertação (Mestrado) Universidade de Brasília, Brasília, 2002. 
PEDRON, F.A.; POELKING, E.L.; DALMOLIN, R.S.D.; AZEVEDO, A.C.; KLANT, E.A Aptidão de uso da terra como base para o planejamento da utilização dos recursos naturais no município de São João do Polêsine, RS. Ciência Rural, v.36, p.105-112, 2006.

RAMALHO FILHO, A.; BEEK, K.J. Sistema de avaliação da aptidão agrícola das terras. Rio de Janeiro: Embrapa-CNPS, 1995. 65p.

SILVA, A.B.; BRITES, R.S.; SOUZA, A.R. Caracterização do meio físico da microbacia quatro bocas, em Angelim, PE, e sua quantificação por sistema de informação geográfica. Pesquisa Agropecuária Brasileira, v.34, p.109-117, 1999.
SILVA, M.T.G. Utilização de geotecnologias no levantamento e adequação do uso dos solos na bacia do Rio João LeiteGoiânia-GO. 2003, 125p. Dissertação (Mestrado) - Faculdade de Agronomia e Medicina Veterinária, UnB, Brasília, 2003.

VALÉRIO, A.M.; SILVA, G.B.S.; KAMPEL, M.; STECH, J.L. Avaliação da classificação não supervisionada do uso do solo e tipos de água no reservatório de Manso, MT. Revista Geografia - Ensino \& Pesquisa, v.12, p.4081-4095, 2008. 